\title{
A 3D REWORKING OF THE URBAN TRANSFORMATIONS OF PALERMO IN RECENT HISTORY FOR A HYPOTHESIS OF A "CITY MUSEUM" BASED ON DIGITAL VISUALIZATIONS
}

\author{
Gian Marco Girgenti, Antonino Alessio
}

Università degli Studi di Palermo - Dipartimento di Architettura

\begin{abstract}
KEY WORDS: Perspective restitution - 3D modeling - 3D printing - Graphic analysis - Disappeared architecture - Immersive digital visualization
\end{abstract}

\begin{abstract}
:
The objective that drives this research is given by a multitude of information which, in addition to the contribution of technology, allows us to study, analyze, verify and remodel the sites, monuments and evolutions of the city through graphic processes of perspective restitution that start from the analysis of historical photos. The drawing methods, the digital graphic rendering and through the aid of geometric techniques, contribute to the reconstruction of projects and architectures that are now lost, this is possible thanks to the methods of perspective, axonometry and three-dimensional restitution.

This remarkable photographic heritage belonging to Palermo, but also to any other city in the world that is sometimes not even considered in the least or that is even forgotten in archives today finds new life thanks to the perspective restitution. Shooting and photographic images following particular studies, allow us to precisely establish the observation points and the dimensions of architectures that have now disappeared, giving them new life through the transposition and reconstruction of the same within a "memory archive three-dimensional ".

In order to describe the transformations of the city, both urban and architectural, we have taken as a case study an architecture that has now been lost in the city of Palermo: villa Rutelli. It was a neo-Gothic villa, built in the first twenty years of the twentieth century on the axis of Via Libertà and demolished in the 1960s along with other buildings of the Palermitan Liberty during the years of the infamous "sack of Palermo". Through the iconographic and archival research at the CRICD and the Bronzetti fund (photographer) and with the aid of research and cataloging studies, illustrative material emerged which was useful for reworking the particularities of the model through the perspective restitution.
\end{abstract}

\section{INTRODUCTION}

"There are images that, more than many others, seem to have the task and the privilege of constituting a rather rare and eloquent testimony of epochs and atmospheres now far from our present.

Images that tell the story of a city through its social and urban events. A story kept among the pages of photographic collections yellowed by time ".

With these words Giuseppe Di Benedetto presents, in his two volumes on "Palermo between the nineteenth and twentieth centuries" the catalog raisonné of the historical postcards of the Di Benedetto Archive, a photographic repertoire of images of the city of Palermo which, read through a systematic and connected reading, provide a precious narration of the transformations undergone by the city in its most recent history, including glimpses of destroyed architecture and visions of spaces that are now irremediably modified.

The recent republishing of the book by Salvatore Mario Inzerillo "Urbanistica e società negli ultimi duecento anni a Palermo" has contributed to the development of an increasingly specific interest to devote to the history of the transformation of the city in more recent times, the period sadly known to the chronicles as "building sack". Beyond identifying precise responsibilities between business-mafia committees and drafting urban plans and architectural projects, the fact that emerges from the analysis of the contemporary city - the Palermo of urban growth and expansion of the 50s - 60- is the evidence of a city that is intrinsically disordered and out of control, not lacking in episodes of architectural quality as regards some sporadic achievements, but absent of an overall view as regards the spaces of collective liveability.

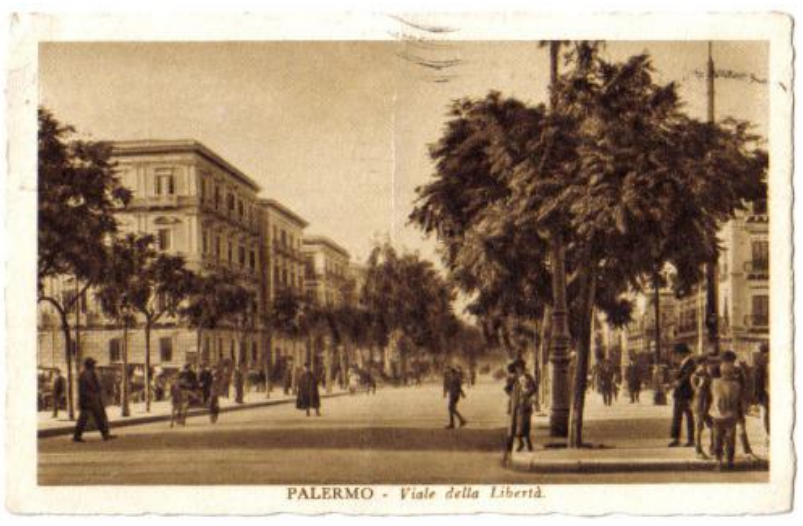

Figure 1. Via della Libertà, historical archive, Palermo.

The patient and meticulous work of re-reading the architecture demolished in this season (almost all private residences built in the early 1900s in the middle of the Sicilian "Belle Epoque") 
and replaced by the new architecture made by Adriana Chirco and Mario Di Liberto in their most recent publications has also determined the awareness of a new civic sense on a part of the citizens in the interest turned towards reconstruction - ideal, often inclined to nostalgic recrimination but always moved by a sincere affection - of those city passages disappearances in which to recognize the evidences of an architectural language and an urban vision (the Liberty of the school of Ernesto Basile) that had also characterized the expansions of the city in the early 1900s. The diffusion via internet of discussion groups in the main social networks has also contributed to the publication of little-known photographic documents, often unpublished because they come from family archives, which properly cataloged and systematized can allow a complete "virtual reconstruction" of the memory of the city disappearance, to be used as a tool for educational workshops to be held in schools or as a contribution to the creation of a "museum of the city and the territory", useful for students and fans of the history of the city.

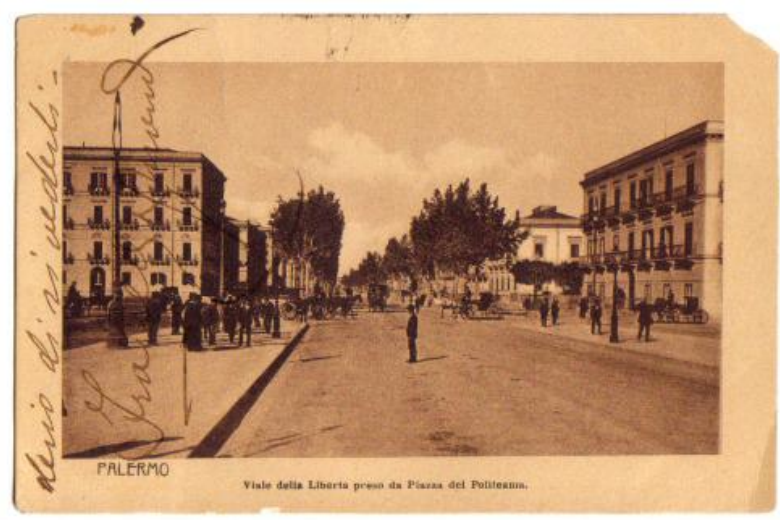

Figure 2. Via della Libertà, historical archive, Palermo.

The goal we set ourselves, on which the focus of our contribution is, is the possibility given by transferring digitally all this information, translating them into navigable threedimensional models, and subsequently being able to create urban scale and detailed models derived from digital models, through $3 \mathrm{D}$ printing procedures.

The story of the lost city and the chronology of the transformations of different conceptions of the urban image thus unfold into a multimedia product in which it is possible to reread and critically place passages of the history of lost architectures otherwise destined for oblivion.

The methodology used makes use of perspective restitution operations carried out on the various frames, recontextualized in the ancient maps appropriately digitized and geo-referenced to the digital maps of the current urban landscape.

The combined use of overlapping layers allows navigation from the $3 \mathrm{D}$ of the current situation back to the situation of the original subdivision, carrying out along the timeline the chronology of transformations, demolitions and reconstructions, or manipulations carried out directly on the single architectural artifact.

Some attention is also given to the mapping of lost or transformed green areas (originally parks and gardens) in finally detecting, in a tangible and immediate way, the increase in building densities and the decisive change in meaning of the architectural / urban environment.
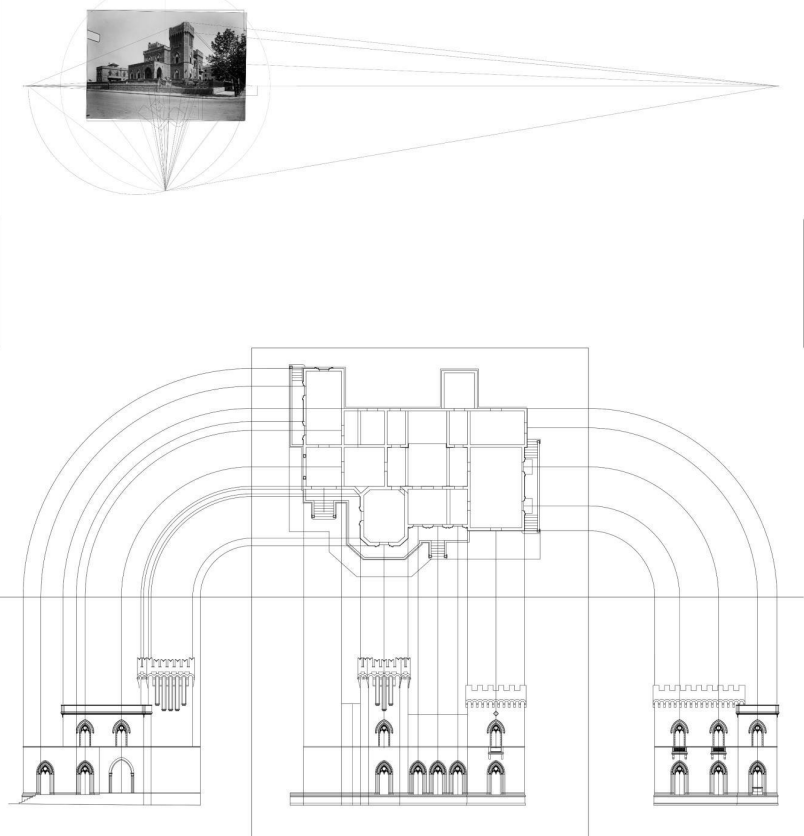

Figure 3. Perspective reconstruction using photos from historical archives.

\section{DISAPPEARED ARCHITECTURE OF PALERMO LIBERTY: VILLA RUTELLI}

Until the second half of the 1700 s, the city of Palermo was still limited within the walls of its ramparts. With the improvement of security conditions, the wall system begins to lose its primary function and thus begins the expansion of the city beyond the limits defined by the wall perimeter. The north-south expansion route appears to be the most natural one, from the extension of Via Maqueda then Via della Libertà towards the Piana dei Colli to the north, until it crosses the Oreto River and reaches Monte Grifone which closes the Piana di Palermo to the south.

The "Via delle Libertà" was traced on March 16, 1848, with the intention of giving work to the great mass of dispossessed after the revolutionary uprisings of the same year.

The feeling of discomfort that assails the minds at the sight of a Palermo that was different from how it is seen today.

Of the "Boulevard" of Palermo, Via Libertà, and its Libertystyle villas all that remains is a long boulevard composed of a mosaic of what remains of liberty villas and modern buildings that alternate ruining the original atmosphere of the Via Libertà of a time. That time that does not refer to a "distant time", but a fairly recent historical time that dates back to the last years of the 1800 s and especially to the early 1900 s.

With the National Exhibition of Palermo of 1891/92, located in the current English Garden of Palermo, a new master plan was 
started that allowed the construction of tree-lined avenues and subdivisions of the land.

In this area, in fact, in the years following the Exposition there will be a real flourishing of Art Nouveau buildings and the area will expand the old historic center of Palermo from Via Dante to Piazza Vittorio Veneto (commonly called "the Statue", due to its imposing commemorative monument created by Ernesto Basile in 1910).

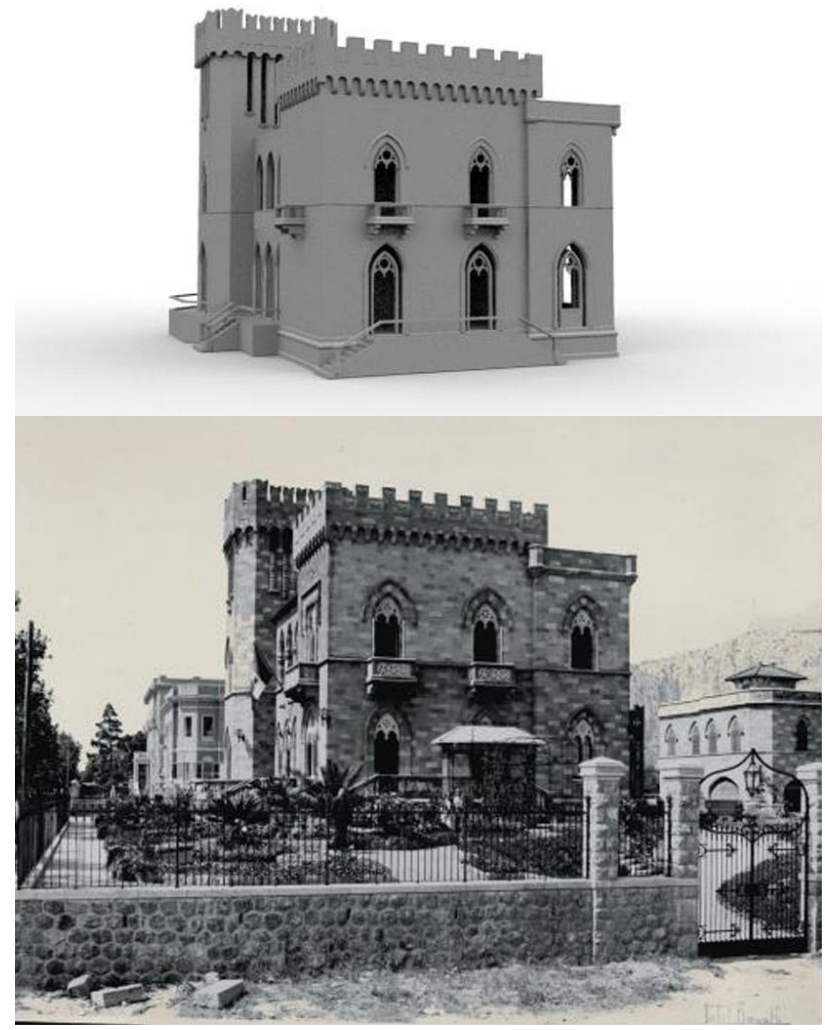

Figure 3. Three-dimensional reconstruction and relative historical photo.

This is the period in which the construction of several Art Nouveau villas began by the architect Ernesto Basile and other contemporary architects. The so-called "villas" become a formula of prestige not only for architects but above all for clients who increasingly require the construction of Art Nouveau villas that enhance the prestige of the family.

But not everything is destined to survive forever, consequently to the collapse of the Palermo bourgeoisie, Palermo will be enveloped by a slow decline that will culminate with the infamous "Sack of Palermo".

The expression "Sack of Palermo" refers to the disfigurement of the city caused by the aggressive subdivision, the so-called "building boom", implemented by the administration of the time in the twenty years following the Second World War. In fact, due to the bombings, part of the old Palermo was destroyed and new homes were needed and it was here that the councilor for public works came into play and granted 4,000 building permits, of which 1,600 were registered in the name of three nominees.
It is stated that over 3,000 of these concessions were signed in the space of a single night and the tone in which these events that led to the change in the urban layout of the beginning of the century are told can only be nostalgia for what no longer exists bitterness for the causes that led to this. Many of the Art Nouveau villas between the late 1950s and 1960s were literally razed to the ground to make way for new buildings or to hide what had to be seen.

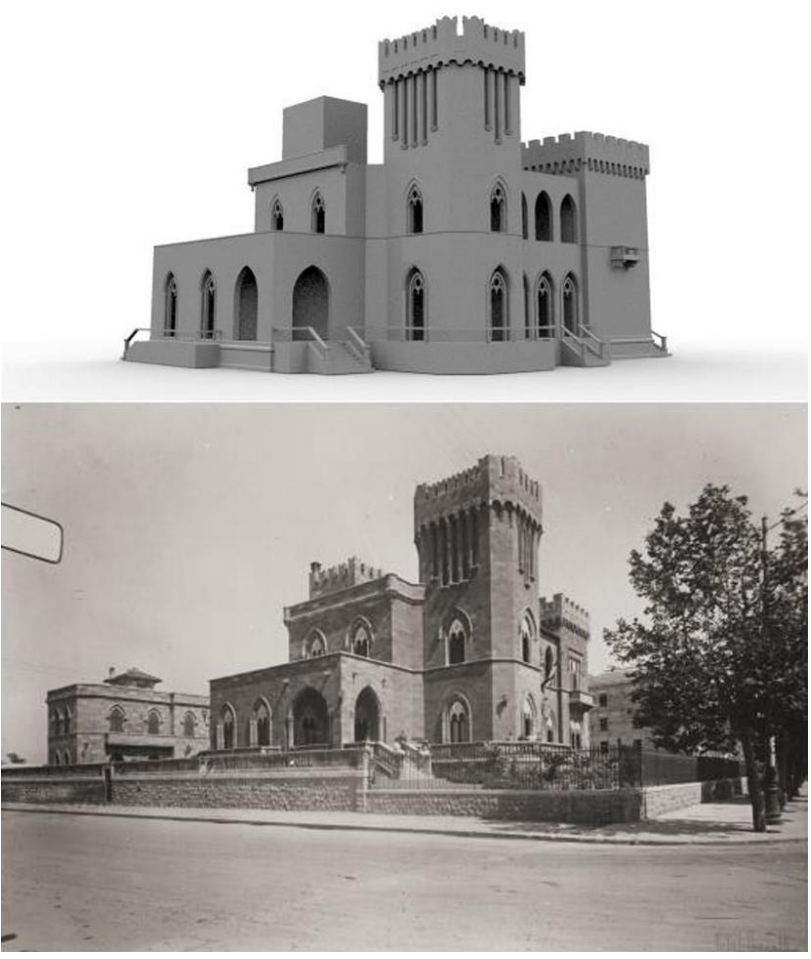

Figure 4. Three-dimensional reconstruction and relative historical photo.

The theme of these topics is linked to the theme of memory and digital reconstruction, trying to highlight the eclectic and neoGothic three-dimensionality of Villino Rutelli, "pearl" of Viale della Libertà demolished due to the events related to the "Sack of Palermo", on a lot facing the exedra of the "Matteotti district".

The Villa, built by the Bonci-Rutelli company, with its multiheight garden and its turreted shape, is technically interesting to be analyzed through "conscious reconstruction", a method that crosses the dynamics of the subject matter of the paper, from Monge's projections to point clouds.

Often, in the case of architectural surveying, the specificities of an object are so complex that it is almost impossible to have a survey tool or method that possesses them all at the same time, and this greatly limits the exclusive use of a system rather than a other and from this arises the need to simultaneously use several methods in a complementary way to achieve the desired goal. The different ability to acquire three-dimensional data and to 
extract and manage 3D data, such as different representations of the real object, underlines a strong complementarity between the various methods and the ability to make the most of the potential of each individual tool.

The study and analysis of Villino Rutelli is strongly due to the work of the photographer Eugenio Bronzetti, who between 1935 and 1940 had documented the interiors and exteriors.
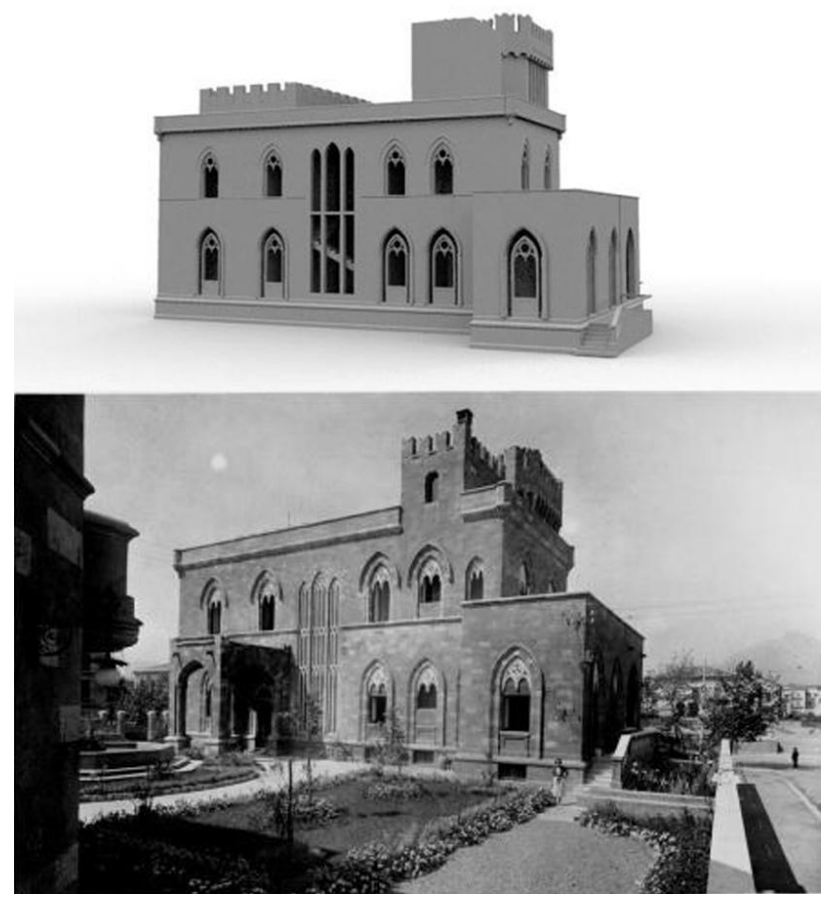

Figure 5. Three-dimensional reconstruction and relative historical photo.

The neo-gothic style villa was an articulated complex of volumes which, among jetties, turrets and arcades, formed a set of remarkable visual impact.

Located in Via della Libertà, at the intersection with Via La Marmora, construction work began in 1930 on a project by the engineer Antonino Mora. It was built by the architect Paolo Bonci and the builder Emanuele Rutelli.

Every detail had been studied with care and with philological intent: from the pointed arch cornices of the openings, to the openings in the lunettes of the windows, to the columns of the arcades, not without some reference to the linearism of the times, such as the thin openings of the turrets.

The villa was famous for its refined interiors in which the themes of the revival of the neo-Gothic style were taken to the extreme.

- all the internal masonry was in small blocks of medieval inspiration;

- large windows, with stained glass in imitation of Gothic cathedrals, illuminated the wooden staircase with a refined design railing;

- fake beams, medieval-themed paintings, style fireplaces, wrought iron chandeliers and refined boisieries recreated the spirit and atmosphere of the medieval era in the halls, without sacrificing contemporary comforts. The garden that surrounded the residence was also vast and well articulated. In it, in addition to fountains and exotic plants, was a small added body, in style with the villa.

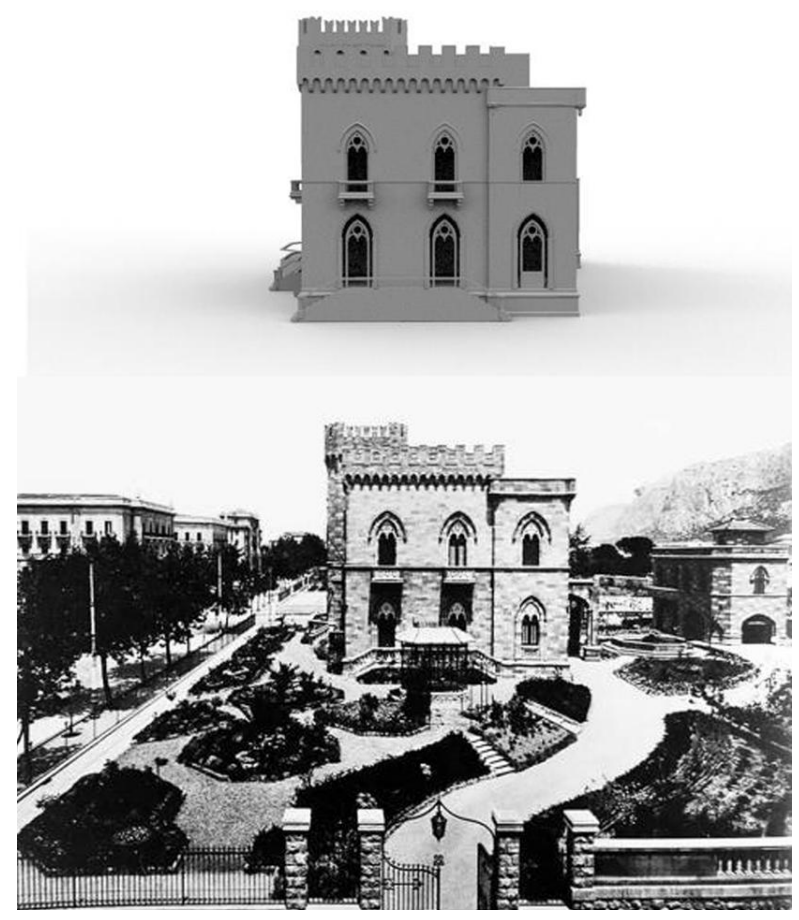

Figure 6. Three-dimensional reconstruction and relative historical photo.

The demolition of the villa deeply affected public opinion, as it was one of the most significant artifacts of the stretch of Via Libertà. In 1968, the year of its demolition after the tragic period of the "Sack of Palermo".

The building complex that now stands in its place is an elegant product of the contemporary architecture of the architect Giuseppe Sindoni: at eight elevations above the attics, the work was built by Giuseppe Monti and covers the entire block. It features innovative formal corner solutions, such as the circular completion turrets; the openings consist of protruding balconies with smoked glass barriers and windows within loggia moldings. 


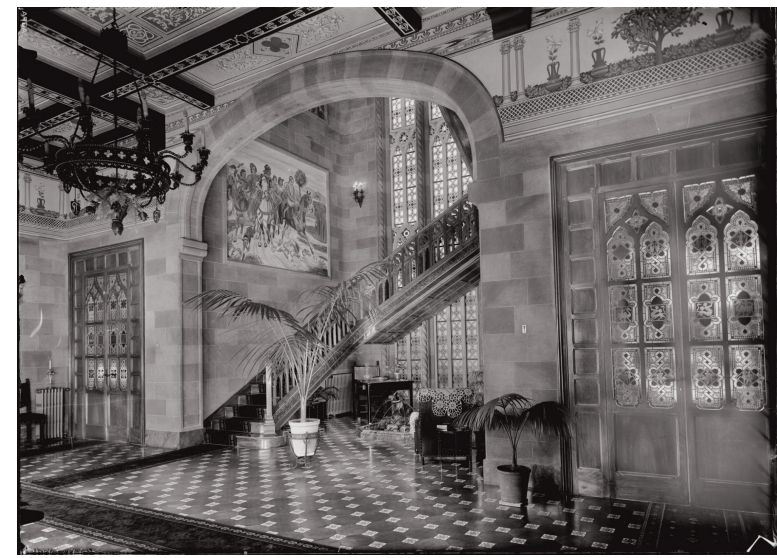

Figure 7. Interior details of Villa Rutelli.

\section{CONCLUSION}

The three-dimensional modeling tool, which lends itself well to the reconfiguration of artifacts and architectural or urban elements that are no longer legible in the current fabric, integrates with interactive and multisensory information systems that make it possible to transform the episodes represented into a real experience through the possibility of interact dynamically and personally with the information contained therein or by simulating realistic walks in the places described.

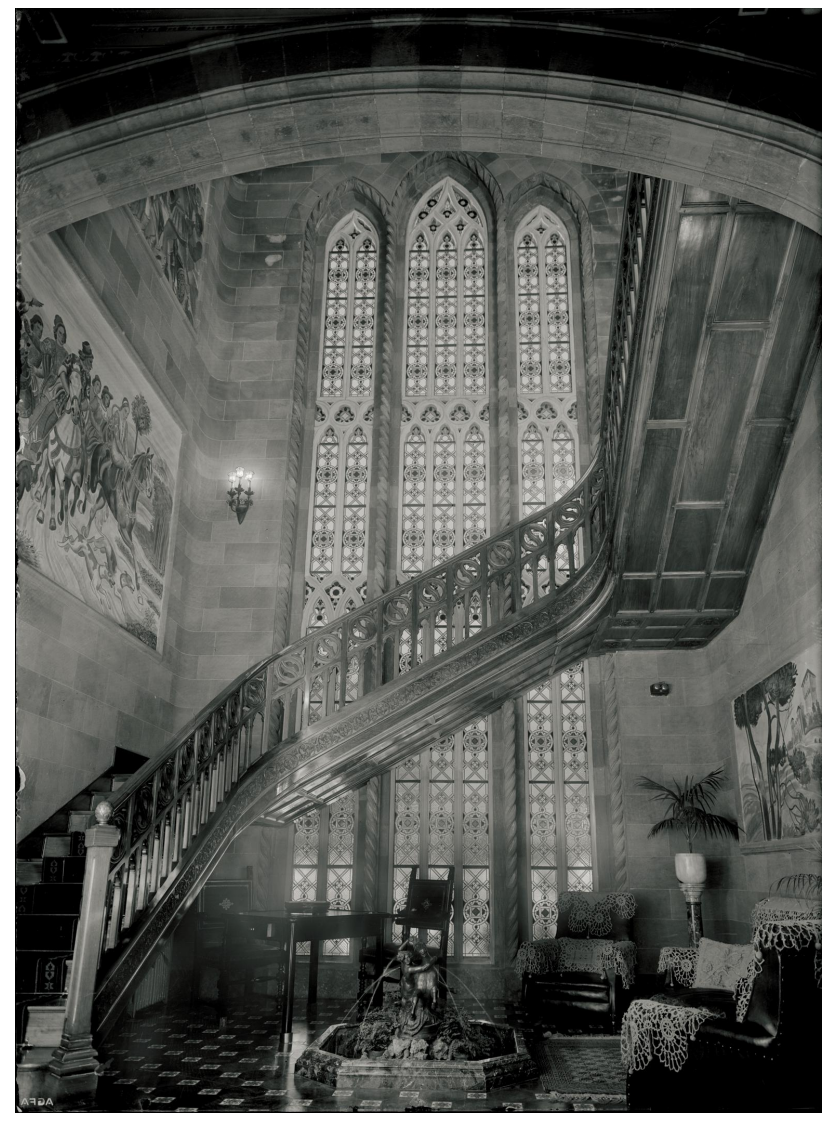

Figure 8. Interior details of Villa Rutelli.
The ways to exploit these technologies can take place remotely (with dynamic views similar to those used by Google Art Project for Maps Street View) or through direct use (through immersive virtual views or applications for portable devices and tablets). These experiments are now quite consolidated in scientific research and in the so-called "edutainment", which collects and disseminates all the multimedia production linked to the history of art and architecture in forms ranging from documentary to video games.
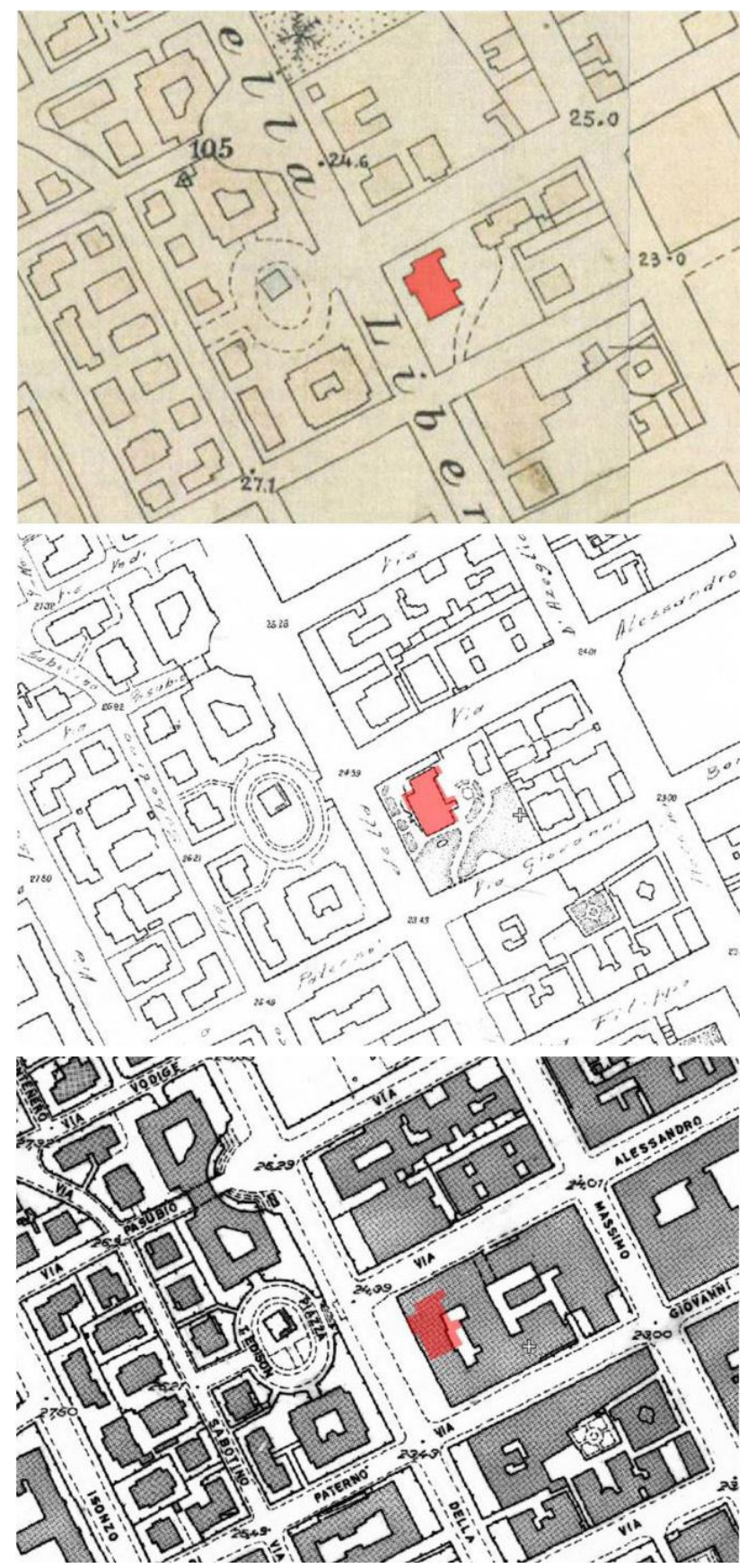

Figure 9. Urban evolution of the area of interest.

The methodology used for the three-dimensional reconfiguration of the lost volumes was mainly based on the information collected from the photographic catalog of the Bronzetti collection, which well documents the interiors and 
exteriors of the building. We worked on these with perspective reconstructions, identifying for each of them the optical cone, the visual axis and the planimetric location of the frame and the point of view; these have been fixed on the historical cartography (OMIRA 1936, IRTA 1954), taken as a reference plane, which has been digitally redesigned to overlap the current site plan, in full scale and appropriately georeferenced.

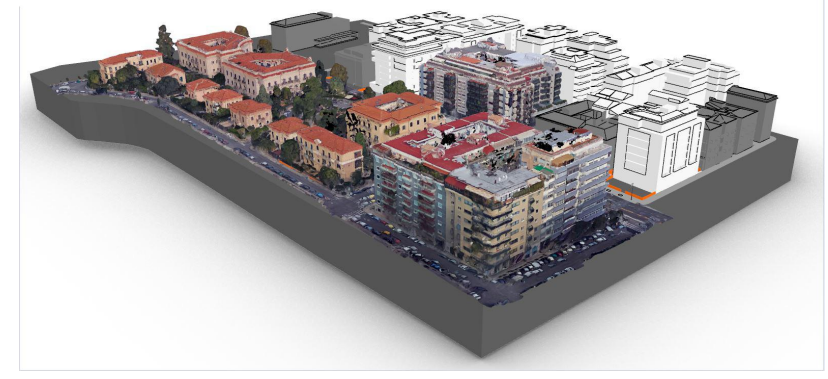

Figure 10. NURBS modelling of the urban contest based on the point cloud acquisition

The project involves the reconstruction and analysis of other notable architectures along the axis of Via Libertà, which shared the same destiny of demolition and which deserve to be preserved in the shared memory of the city, for a hypothesis of virtual reconfiguration of the urban image of Palermo of the "Belle Epoque".

The simulations in immersive visualization can be used for a hypothesis of a "Museum of the City", focused on the lost Liberty and the most recent urban transformations.

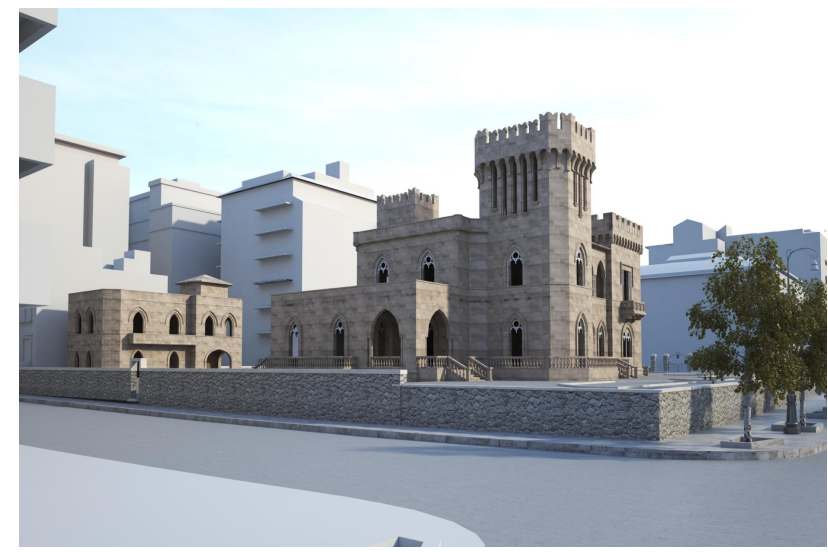

Figure 11. 3d model contextualized in the current model.

The patient and meticulous work of rereading the architecture demolished in this season and replaced by the new architecture made in some recent publications has also determined the awareness of a new civic sense on a part of the citizens in the interest turned towards reconstruction - ideal, often inclined to nostalgic recrimination but always moved by a sincere affection -of those city passages disappearances in which to recognize the evidences of an architectural language and an urban vision (the Liberty of the school of Ernesto Basile) that had also characterized the expansions of the city in the early 1900s. The diffusion via internet of discussion groups in the main social networks has also contributed to the publication of little-known photographic documents, often unpublished because they come from family archives, which properly catalogued and systematized can allow a complete "virtual reconstruction" of the memory of the city disappearance, to be used as a tool for educational workshops to be held in schools or as a contribution to the creation of a "museum of the city and the territory", useful for students and fans of the history of the city. Another field of interest is the use of reconfiguration and virtual display systems within museum teaching laboratories for young students: among the school initiatives of the programs "The school adopts the city", for both primary and secondary school classes, retrospectives dedicated to the disappeared architecture are never missing, focused above all on the center of the axes via Libertà / via Notarbartolo, theater of the most striking and systematic demolitions.
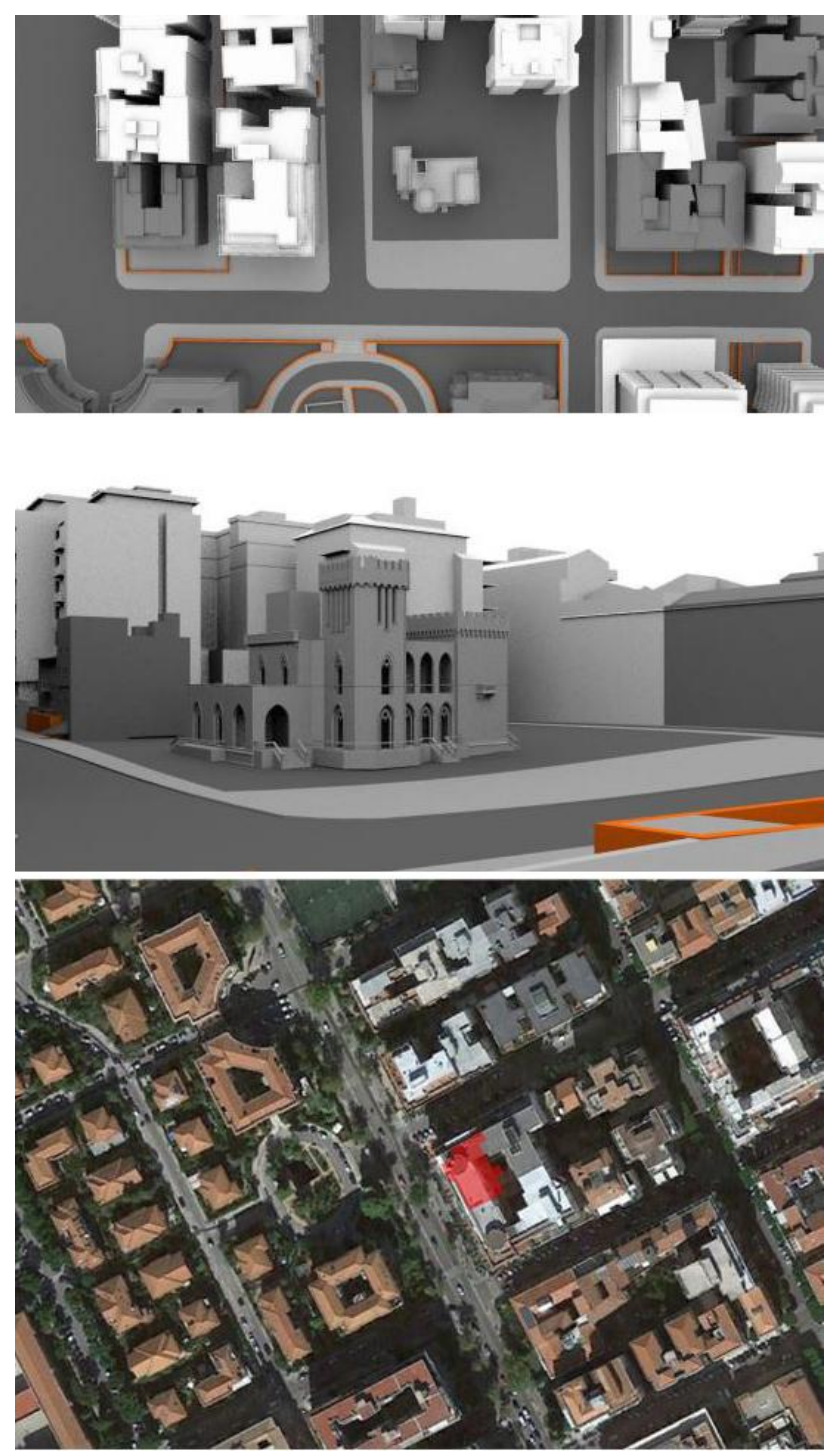

Figure 12. Perspective reconstruction of the current area of interest and overall view with the inclusion of Villa Rutelli. 


\section{REFERENCES}

Aloi A., 2015. Paolo Bonci architetto : interventi urbanistici per una "Grande Palermo". Tesi di laurea, relatore Prof. Vesco M., correlatore Arch. Rubbino G., Università degli Studi di Palermo, Scuola Politecnica, Dipartimento di Architettura, Corso di laurea in Scienze della Pianificazione Territoriale, Urbanistica, Paesaggistica e Ambientale, Palermo.

Barbera Azzarello C., 1980. Raffigurazioni, ricostruzioni, vedute e piante di Palermo (dal XII al XIX sec.), Edigraphica Sud Europa, Palermo.

Basile N., 1978. Palermo Felicissima: Divagazioni d'arte e di storia, Pietro Vittorietti Editore, Palermo.

Bellafiore G., 1995. Palermo. Guida della città e dei dintorni, Palermo.

Bonacini E., 2011. Nuove tecnologie per la fruizione $e$ valorizzazione del patrimonio culturale, Aracne Editrice, Roma.

Bonci P., 1943. Piano regolatore di massima urbanistico ed economico per la città di Palermo e la Conca d'Oro, Palermo.

De Seta C., Di Mauro L., 1981. Palermo, Laterza, Roma.

Di Benedetto G., 2009. Palermo tra Ottocento e Novecento. La città entro le mura nella collezione fotografica di Enrico Di Benedetto, Grafill, Palermo.

Docci M, Fiorucci T., 2005. Metodologie innovative per il rilevamento dell'architettura e dell'ambiente, Gangemi Editore, Roma.

Fantini A., 2016. Scan2BIM: processi e metodologie per il rilievo digitale e la restituzione parametrica e semantica della Rocca di Reggiolo in modello BIM . Tesi di laurea, relatore Prof. Ing. Remondino F., correlatore Ing. Garagnani S., Università di Bologna, Scuola di Ingegneria e Architettura, Corso di laurea specialistica europea in Ingegneria Edile/Architettura, Bologna.

Filosto R., 1868. Lineamenti Teorici del Disegno, II edizione, Edizioni i.l.a. Palma, Palermo.

Gambino M. M., Il paradiso della terra. Palermo fuori le mura, Edizioni Brotto, Palermo 1989.

Ippoliti E., 1989. Rilevare: comprendere, misurare, rappresentare, Edizioni Kappa, Roma 2000.

La Duca R., 1975. Cartografia generale della città di Palermo e antiche carte della Sicilia, Edizioni scientifiche italiane, Napoli.

La Duca R., 1975. La città perduta: cronache palermitane di ieri e di oggi, Edizioni scientifiche italiane, Napoli.

La Duca R., 1990. Palermo ieri e oggi, Sigma Edizioni, Palermo.

Lima A.J., 1982. Storia dell' urbanistica 2/3 - Palermo: via Libertà 1848/1851, Edizioni Kappa, Roma.

Maldonando T., 1994. Reale e virtuale, Feltrinelli Editore, Milano.
Marsiglia N., 2013. La ricostruzione congetturale dell'architettura: storie, metodi, esperienze applicative, Grafill, Palermo.

Quartarone C., 2008. Sessa E., Mauro E. (a cura di), Arte e Architettura liberty in Sicilia, Grafill, Palermo.

Sessa E., Itinerario III, 2008: Una piccola capitale dell'Art Nouveau. Palermo, allegato a Quartarone C., Sessa E., Mauro E. (a cura di), Arte e Architettura liberty in Sicilia, Grafill, Palermo.

Sica P., 1980. Storia dell'Urbanistica - Il Novecento, Barci. 